\title{
Hydrogel Microencapsulated Insulin-Secreting Cells Increase Keratinocyte Migration, Epidermal Thickness, Collagen Fiber Density, and Wound Closure in a Diabetic Mouse Model of Wound Healing
}

\author{
Ayesha Aijaz, BS, Renea Faulknor, BS, François Berthiaume, PhD, and Ronke M. Olabisi, PhD
}

Wound healing is a hierarchical process of intracellular and intercellular signaling. Insulin is a potent chemoattractant and mitogen for cells involved in wound healing. Insulin's potential to promote keratinocyte growth and stimulate collagen synthesis in fibroblasts is well described. However, there currently lacks an appropriate delivery mechanism capable of consistently supplying a wound environment with insulin; current approaches require repeated applications of insulin, which increase the chances of infecting the wound. In this study, we present a novel cell-based therapy that delivers insulin to the wound area in a constant or glucose-dependent manner by encapsulating insulin-secreting cells in nonimmunogenic poly(ethylene glycol) diacrylate (PEGDA) hydrogel microspheres. We evaluated cell viability and insulin secretory characteristics of microencapsulated cells. Glucose stimulation studies verified free diffusion of glucose and insulin through the microspheres, while no statistical difference in insulin secretion was observed between cells in microspheres and cells in monolayers. Scratch assays demonstrated accelerated keratinocyte migration in vitro when treated with microencapsulated cells. In excisional wounds on the dorsa of diabetic mice, microencapsulated RIN-m cells accelerated wound closure by postoperative day 7; a statistically significant increase over AtT-20ins-treated and control groups. Histological results indicated significantly greater epidermal thickness in both microencapsulated RIN-m and AtT-20ins-treated wounds. The results suggest that microencapsulation enables insulin-secreting cells to persist long enough at the wound site for a therapeutic effect and thereby functions as an effective delivery vehicle to accelerate wound healing.

\section{Introduction}

$\mathbf{S}$ KIN ACTS AS A protective barrier against environmental toxins and provides thermoregulation and fluid homeostasis. ${ }^{1}$ Any injury to the skin results in its loss of structural and functional integrity. Following injury, a wound healing cascade sets into play in three sequential phases that dynamically interact and overlap in time. The inflammatory response is the key to effective wound healing. Macrophages prepare the wound bed by clearing tissue debris, which allows new vessel formation and infiltration of fibroblasts and nutrients to begin healing. ${ }^{2}$ Nonhealing wounds have a hyperglycemic wound environment that causes immune cells to produce proinflammatory cytokines and impairs phagocytosis.

If inflammation is not controlled and inflammatory cells persist in the wound site, it may lead to chronic inflammation. In chronic inflammation, activated neutrophils enter a selfsustaining cycle characterized by a continuous breakdown of wound matrix by oxidative enzymes such as matrix metalloproteases (MMPs). ${ }^{3}$ In this environment, MMPs rapidly degrade extracellular matrix components deposited by fibroblasts. ${ }^{4}$ The end result is decreased angiogenesis, reepithelialization, wound contraction, and reduced wound strength.

The use of insulin for wound healing applications dates back to the 1920s. One of the earliest studies by Rosenthal showed that rats treated with a topical insulin suspension demonstrated increased wound tensile strength. ${ }^{5}$ Insulin has also been shown to promote closure of in vitro wound models by activating the ERK1/2 and PI3K signaling. ${ }^{6}$ Binding of bioactive insulin to the insulin receptor leads to autophosphorylation of the receptor, which activates downstream signaling proteins such as PI3K and ERK. Activation of PI3K results in subsequent activation of its

Department of Biomedical Engineering, Rutgers University, Piscataway, New Jersey.

(C) A. Aijaz et al. 2015; Published by Mary Ann Liebert, Inc. This Open Access article is distributed under the terms of the Creative Commons Attribution Noncommercial License (http://creativecommons.org/licenses/by-nc/4.0/) which permits any noncommercial use, distribution, and reproduction in any medium, provided the original author(s) and the source are credited. 
downstream target AKT. The PI3K/AKT pathway is activated in an insulin-dependent manner and is implicated in wound healing. Insulin also prevents apoptotic cell death induced by inflammatory stimuli by counteracting the dephosphorylation of AKT by TNF- $\alpha$ and promotes angiogenesis by stimulating expression of VEGF through AKT signaling. ${ }^{7}$

Rabinowitch reported disturbed sugar metabolism in nondiabetic patients presenting with slow wound healing arrested in the inflammatory phase. ${ }^{8,9}$ Blood samples in these patients did not meet the diagnostic criteria for diabetes, but abnormal blood sugar time curves were observed. Their findings suggest that carbohydrate metabolism may be disturbed during wound healing and may actually be impairing wound repair when infection is present. Insulin regulates and induces the infiltration of macrophages, thereby promoting resistance to infection by eliminating pathogens and clearing cellular debris. ${ }^{10}$

Insulin plays a vital role in several cellular processes and serves as a chemoattractant and mitogen for cells necessary for wound healing, promoting growth, proliferation, secretion, and migration of keratinocytes, endothelial cells, and fibroblasts, all of which are essential in wound healing. ${ }^{11}$ For instance, insulin is essential for glucose utilization by fibroblasts when they are producing collagen and its exogenous application increases collagen deposition ${ }^{4}$; the proliferation and migration of endothelial cells are necessary for the formation of new blood vessels, both of which are promoted by insulin; and this insulin-mediated angiogenesis results in vessels that deliver the required nutrients and oxygen to the injured tissue, which thereby accelerates wound healing. Liu et al. demonstrated that insulin injection in mouse skin stimulated angiogenesis and led to longer and more branched blood vessels. ${ }^{12}$

Chen et al. showed that insulin regulated the wound inflammatory response even in nondiabetic animals by inducing advanced infiltration and resolution of macrophages. ${ }^{10}$ Lima et al. reported attenuation of insulin signaling pathways in the skin of diabetic animals and an increase in the time to complete wound closure; topically applied insulin cream improved wound healing rates in these animals. ${ }^{13}$

Thus, exogenous insulin administration can be effective in accelerating wound healing in both diabetic and nondiabetic animals. ${ }^{14-18}$ Diabetic foot ulcers constitute a devastating subset of chronic wounds affecting the diabetic population, with estimates as high as $25 \%$ of all diabetics developing a foot ulcer in their lifetime. ${ }^{19,20}$ These chronic ulcers have a propensity to infection and are one of the most common causes of amputations and morbidity in diabetic patients. Therapeutic approaches such as local debridement, skin grafts, dermal scaffolds, and growth factor treatments often yield less than satisfactory results due to the proinflammatory state of the wound. ${ }^{21}$ Thus, there is a pressing need to develop therapies that can regulate the proinflammatory wound environment.

Insulin regulates the inflammatory state by regulating the hyperglycemic wound environment. ${ }^{10}$ However, one barrier to widespread use of topical insulin therapies is the lack of a delivery system that maintains a steady dose and does not require repeated exposure of the wound. Other applications have successfully used cell therapies to achieve constant delivery of therapeutic products. Internal cell therapies have shown improved success when cells are enclosed in a barrier that protects them from the host immune response, thereby prolonging the viability and secretory characteristics of the cells. ${ }^{22-24}$ Subcutaneous implantation of poly(ethylene glycol) diacrylate (PEGDA)-encapsulated human islets in type I diabetic patients has shown promising results of islet function with no evidence of autoimmune reaction. ${ }^{23}$ PEGDA encapsulation has permitted successful transplantation of xenogeneic pancreatic islet cells: when porcine islets were implanted into diabetic rats, the animals achieved normoglycemia. ${ }^{24}$ In fact, pancreatic islet cells encapsulated within PEGDA injected into diabetic humans and animals have successfully returned them to normoglycemia without the tissue typing required when these cells are not encapsulated. 22,24

No external cell-based therapy involving insulin-secreting cells has yet been reported for treating chronic wounds. Herein, we describe a system that provides a sustained and steady dose of insulin to regulate the hyperglycemic wound environment characteristic of diabetic and chronic wounds. Through immunoisolation, the microencapsulation system preserves cell viability and the released bioactive insulin accelerates wound closure without the need for multiple applications.

\section{Materials and Methods}

\section{Cell culture}

The constant insulin-producing rat insulinoma beta cell line, RIN-m, and the glucose-stimulated insulin-releasing mouse sarcoma line, GLUT-2 cDNA-transfected AtT-20ins(CGT6) cells, were purchased from American Type Culture Collection (ATCC, Manassas, VA) and propagated in RPMI-1640 medium (ATCC) or Dulbecco's modified Eagle's medium (DMEM; Sigma, St. Louis, MO), respectively, supplemented with $10 \%$ fetal bovine serum (FBS; Sigma) and $1 \% \mathrm{w} / \mathrm{v}$ penicillin-streptomycin (pen-strep; Sigma) in a humidified incubator at $37^{\circ} \mathrm{C} / 5 \% \mathrm{CO}_{2}$.

\section{Microencapsulation}

Cell-laden microspheres were formed as previously reported. ${ }^{25,26}$ Briefly, hydrogel precursor solution was formed by combining $0.1 \mathrm{~g} / \mathrm{mL} 10 \mathrm{kDa}$ PEGDA (10\% w/v; Laysan Bio, Inc., Arab, AL) with (1.5\% v/v) triethanolamine/HEPESbuffered saline ( $\mathrm{pH}$ 7.4), $37 \mathrm{mM}$ 1-vinyl-2-pyrrolidinone, $0.1 \mathrm{mM}$ eosin-Y, and RIN-m cells or AtT-20ins cells for a final concentration of $1.5 \times 10^{4}$ cells $/ \mu \mathrm{L}$. A hydrophobic photoinitiator solution containing 2,2-dimethoxy-2-phenyl acetophenone in 1-vinyl-2-pyrrolidinone $(300 \mathrm{mg} / \mathrm{mL})$ was combined in mineral oil ( $3 \mu \mathrm{L} / \mathrm{mL}$, embryo tested, sterile filtered; Sigma). The cellprepolymer suspension was added to the mineral oil solution, emulsified by vortexing for $4 \mathrm{~s}$ in ambient light, then for an additional 3 s under white light, then the vortex was stopped, and the emulsion was exposed to white light for $20 \mathrm{~s}$ with a vortex pulse at $10 \mathrm{~s}$. Cross-linked microspheres were isolated by addition of $1 \mathrm{~mL}$ complete media, followed by centrifugation at $300 \mathrm{~g}$ for $5 \mathrm{~min}$. The oil layer was removed by aspiration and pelleted microspheres were resuspended in media and placed in transwells $(0.4 \mathrm{~mm}$ pore polycarbonate membrane Transwell inserts; Corning, Inc., Lowell, MA) in a 12-well plate with $3 \mathrm{~mL}$ culture medium. Microencapsulated cells were maintained in a humidified incubator at $37^{\circ} \mathrm{C} / 5 \% \mathrm{CO}_{2}$.

For glucose stimulation studies and cell migration studies, $3 \times 10^{6}$ insulin-secreting cells were encapsulated and $1 \times 10^{6}$ 
insulin-secreting cells were plated on six-well tissue culture plates for comparisons. A higher count of cells was chosen for microencapsulation to account for the $37 \%$ microencapsulation efficiency of our procedure, which we initially determined while developing the microencapsulation protocol. Briefly, three $20 \mu \mathrm{L}$ samples of microencapsulated cells from each group were placed in transwells in a 24-well plate with $1 \mathrm{~mL}$ of culture medium. Monolayer cells were trypsinized, counted with a hemocytometer, and a serial dilution was used as a standard curve. CellTiter $96^{\circledR}$ AQueous One Solution Reagent (Promega Corporation, Madison, WI) at $200 \mu \mathrm{L}$ was added into each well and the plate was incubated for $3 \mathrm{~h}$ in a humidified incubator at $37^{\circ} \mathrm{C} / 5 \% \mathrm{CO}_{2}$. The amount of soluble formazan produced by cellular reduction of the tetrazolium compound [3-(4,5-dimethylthiazol-2-yl)-5(3-carboxymethoxyphenyl)-2-(4-sulfophenyl)-2H-tetrazolium, inner salt; MTS] was measured by reading the absorbance of the medium at $490 \mathrm{~nm}$. Standard curves were used to calculate the number of live cells within microspheres, which in turn was used to determine the encapsulation efficiency. Since encapsulation efficiency was reproducibly 37\%, 270\% more cells were encapsulated when comparing against monolayer cells to equalize cell numbers between microencapsulated cell groups and monolayer groups.

\section{Cell viability}

Encapsulated cell viability was assessed on days 1, 3, 5, 7, 14 , and 21 by incubating microsphere samples in media and $2 \mathrm{mM}$ calcein acetoxymethyl ester and $4 \mathrm{mM}$ ethidium homodimer (LIVE/DEAD Viability/Cytotoxicity Kit for mammalian cells; Life Technologies, Grand Island, NY) for $10 \mathrm{~min}$ at $37^{\circ} \mathrm{C}$ in a humidified $5 \% \mathrm{CO}_{2}$ incubator, then imaging the microencapsulated cells under an epifluorescent microscope (Zeiss Axiovert Observer Z1 Inverted PhaseContrast Fluorescent Microscope). Green fluorescent images for live cells and red fluorescent images for dead cells were separately processed on ImageJ software (Rasband, National Institutes of Health [NIH], Bethesda, MD) to obtain cell counts.

\section{Static glucose stimulation}

Cells in the monolayer or microspheres were maintained in complete culture medium at $37^{\circ} \mathrm{C}$ in a humidified $5 \%$ $\mathrm{CO}_{2}$ incubator. After $48 \mathrm{~h}$, microencapsulated cells and monolayer cells were washed twice with Krebs-Henseleit buffer (KHB; BIOTANG, Inc., Lexington, MA) containing $0.1 \%$ bovine serum albumin (Sigma) and preincubated in KHB without glucose for $60 \mathrm{~min}$. Glucose was then added to the KHB to obtain glucose concentrations of $0.67,1.67,2.8$ and $5.56 \mathrm{mM}$. Each concentration was used to perform static glucose incubations with each cell type for $2 \mathrm{~h}$. At the end of the stimulation period, the incubation buffer was collected from each well and stored at $-20^{\circ} \mathrm{C}$ until analysis. The insulin concentration of the samples was measured by the enzyme-linked immunosorbent assay (ELISA) kit (EMD Millipore, Billerica, MA).

\section{Keratinocyte scratch assay}

Human keratinocytes (HaCaT; Addex Bio, San Diego, CA) were propagated in DMEM (Sigma) supplemented with
10\% FBS (Sigma) and pen-strep (Sigma) in a humidified incubator at $37^{\circ} \mathrm{C} / 5 \% \mathrm{CO}_{2}$. For scratch assays, 180,000 $\mathrm{HaCaT}$ cells/well were seeded onto 24-well plates (Greiner Bio-one, Monroe, NC). Cells were cultured for $48 \mathrm{~h}$ to form a confluent monolayer, at which time a single scratch of $175 \pm 60 \mu \mathrm{m}$ was produced in the center of the well with a 10$\mu \mathrm{L}$ pipette tip. The wells were washed twice with Dulbecco's phosphate-buffered saline (Sigma) to remove cell debris. $\mathrm{HaCaT}$ cells were then stimulated with conditioned media from (1) empty microspheres (control); (2) microencapsulated RIN-m cells on days 1,7 , or 21 ; (3) microencapsulated AtT20 ins cells on days 1,7 , or 21 ; (4) monolayer RIN-m cells on day 1; or (5) monolayer AtT-20ins cells on day 1. RIN-m and AtT-20ins cells were not maintained in monolayers beyond 4 days since the cells became overconfluent, resulting in cell death too great to collect insulin-conditioned media on days 7 and 21 . HaCaT cell migration across the scratch was imaged at 0,4 , and $24 \mathrm{~h}$ using phase-contrast microscopy and analyzed on NIH ImageJ software.

\section{Animal studies}

A pilot animal study was performed to determine whether positive in vitro results could be translated to promising in vivo results. All procedures were performed in accordance with protocols approved by the Rutgers University Institutional Animal Care and Use Committee. Genetically diabetic male mice (BKS.Cg-Dock $7^{\eta}+/+L e p r^{d b} / \mathrm{J} ; 10$ weeks old, $n=9$; Jackson Laboratories, Bar Harbor, ME) were anesthetized with isoflurane (Henry Schein, Melville, NY) adjusted as needed, vaporized in $1 \mathrm{~L} \mathrm{O}_{2}$ per minute, and kept on a heating pad at $37^{\circ} \mathrm{C}$. Anesthesia was deemed sufficient when the animal lacked a contracting reflex in response to a toe pinch.

A standardized $1 \times 1 \mathrm{~cm}$ template was used to mark their dorsa, and full-thickness wounds (epidermis, dermis, and underlying panniculus carnosus) were created by excising the marked dorsal skin. Microencapsulated RIN-m or AtT20ins cells or empty microspheres were applied to wounds, which were then covered with Tegaderm ${ }^{\mathrm{TM}}$ and photographed at postoperative days (POD) 3, 7, 14, 21, 28, and 35 for gross appearance. Tegaderm began to fail on POD 16 and therefore all microspheres were then removed. Wound area was measured by tracing the wound margins using ImageJ. Wound closure was calculated as percent area of original wound. Animals were sacrificed by $\mathrm{CO}_{2}$ inhalation on POD 35 and wound tissue was explanted for histology.

\section{Histological analysis}

Wound tissues were fixed in $10 \%$ formalin for $24 \mathrm{~h}$ at room temperature, and then stored in $70 \%$ ethanol at $4{ }^{\circ} \mathrm{C}$ until serial sectioning ( $5 \mu \mathrm{m}$ thick) and staining with hematoxylin and eosin (H \& E) or Picric Acid Sirius Red (PASR) at the Digital Imaging and Histology Core, Rutgers NJMS Cancer Center. Histological images were analyzed on ImageJ software to find epidermal and dermal thickness and collagen density. $\mathrm{H} \&$ E-stained sections were analyzed in ImageJ to measure the thickness of epidermis and dermis using the line selection tool. Lines were created across the thickness of the epidermal or dermal boundaries at five random locations in each $\mathrm{H} \& \mathrm{E}$ section and lengths were averaged. RGB images of PASR-stained sections were 
converted to grayscale by splitting the images into red, green, and blue channels. For accurate visual determination of image threshold for collagen-stained areas, the red channel was selected as it yielded the best contrast between the stain and the background. The thresholded images were analyzed to measure percent area of collagen density. ${ }^{27}$

\section{Statistical analyses}

All data were taken in triplicate and reported as mean \pm standard deviation. Viability, insulin release, scratch closure, dermal and epidermal thickness, collagen density, and wound closure were compared between the different treatment groups using one-way analysis of variance. Pairwise comparisons were made between groups using Fisher's least significant difference post hoc test. $p$-Values $<0.05$ were considered significant. All analyses were performed using KaleidaGraph statistical software version 4.1.0, Synergy Software (Reading, PA).

\section{Results}

\section{Effect of microencapsulation on cell viability}

The cell viability/cytotoxicity assay demonstrated the effect of microencapsulation on cell viability. Live cells within microspheres were identified based on intracellular enzymatic conversion of nonfluorescent calcein-AM to green fluorescent calcein, while ethidium homodimer-1 penetrated damaged membranes of dead cells and, upon binding to nucleic acids, fluoresced bright red (Fig. 1). Microencapsulated RIN-m cell viability was $66.5 \% \pm 8.8 \%$ on day 1 and dropped to $80 \%$ of the initial encapsulated cell viability on day $7(53.9 \% \pm 3.7 \%)$, and then to $64 \%$ of the initial viability postencapsulation on day $21(42.6 \% \pm 7.7 \%)$ (Fig. 2). Microencapsulated AtT-20ins cells demonstrated higher cell viability at $70.6 \% \pm 8.23 \%$ on day 1 , which dropped to $82.5 \%$ of the starting viability by day 7 $(58.2 \% \pm 17.9 \%)$ and $66 \%$ of the initial viability on day 21 $(46.6 \% \pm 9.9 \%)$.

\section{Insulin release kinetics}

Both monolayer and microencapsulated RIN-m cells did not respond to glucose stimulation and maintained a constant insulin secretion profile when exposed to incremental concentrations of glucose and on average secreted $0.48 \pm 0.03$ and $0.35 \pm 0.16 \mathrm{ng} / \mathrm{mL} / \mathrm{h}$ insulin, respectively (Fig. 3A). AtT-20ins cells responded to glucose stimulation and demonstrated significant increases in insulin secretion at incremental glucose concentrations (Fig. 3B). Maximum increases in insulin release were observed at $5.56 \mathrm{mM}$ glucose: for the monolayer, $0.53 \pm 0.05 \mathrm{ng} / \mathrm{mL} / \mathrm{h}$, and for encapsulated cells, $0.66 \pm 0.12 \mathrm{ng} / \mathrm{mL} / \mathrm{h}$, which corresponded to insulin increases of 3.9 and 3.6-fold greater than control
FIG. 1. Representative images of viability stains of microencapsulated AtT-20ins (A-F) and RIN-m (G-L) cells using a LIVE/DEAD ${ }^{\circledR}$ Viability/Cytotoxicity Kit for mammalian cells (Invitrogen, Molecular Probes, Eugene, OR). Stains of microencapsulated AtT-20ins cells on (A) day 1, (B) day 3, (C) day 5, (D) day 7, (E) day 14 , and (F) day 21. Stains of microencapsulated RIN-m cells on (G) day $1,(\mathbf{H})$ day 3 , (I) day 5, (J) day 7, (K) day 14, and (L) day 21. Dead cells appear red and live cells appear green. Scale bars $=$ $100 \mu \mathrm{m}$. Color images available online at www .liebertpub.com/tea
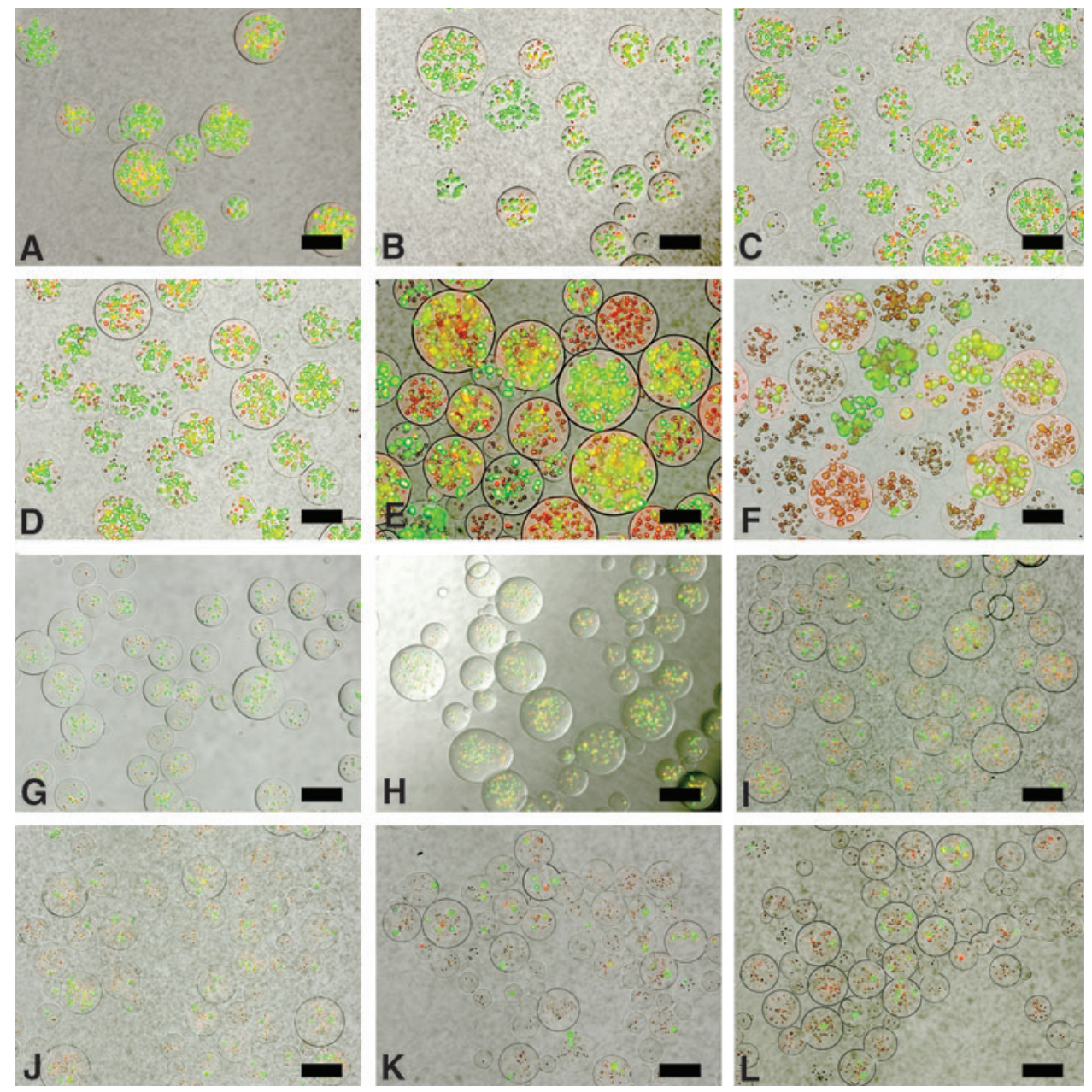


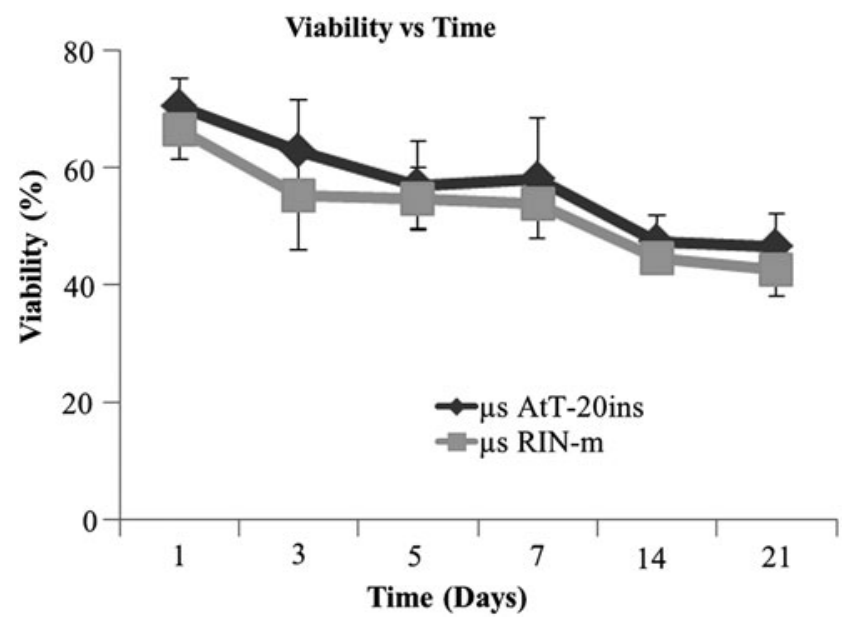

FIG. 2. Percentage viability curve of microencapsulated cells over time. Microencapsulated RIN-m ( $\mu$ S RIN-m) and microencapsulated AtT-20ins ( $\mu$ s AtT-20ins) cell viabilities were not statistically distinct at any time point. $66.5 \% \pm 8.8 \%$, while that of $\mu$ s AtT-20ins cells started at $70.6 \% \pm 8.23 \%$. Viabilities of both cell types gradually decreased over time by $\sim 20 \%$ to $42.6 \% \pm 7.68 \%$ ( $\mu$ s RIN$\mathrm{m})$ and $46.6 \% \pm 9.9 \%$ ( $\mu$ s AtT-20ins) by day 21. Error bars show standard error of mean.

(0 mM glucose) for monolayer and encapsulated cells, respectively. No significant difference in insulin release was observed between microencapsulated and monolayer cells.

\section{Insulin stimulated cell migration}

Bioactivity of the insulin released from microencapsulated insulin-secreting cells was assessed by demonstrating their effect on keratinocyte migration. Keratinocytes were plated in a monolayer to simulate the epidermal layer of the skin and a defect (scratch assay) was created to simulate wound healing in vitro (Fig. 4). Conditioned media containing insulin released from RIN-m microspheres sampled on day 1 demonstrated significantly increased rate of scratch closure compared with media from control empty microspheres $(p<0.05)$ (Fig. 5A). The concentration of insulin from

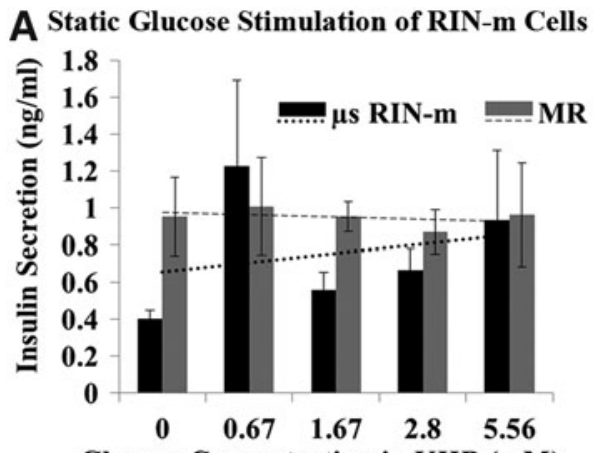

Glucose Concentration in KHB (mM) The viability of $\mu \mathrm{s}$ RIN-m cells on day 1 started at

sampled media is shown in Figure 6. For RIN-m cells, monolayers had the highest concentration of insulin, while for AtT-20ins cells, day 21 microencapsulated cells had the highest insulin concentrations. The rate of scratch closure was $29.5 \pm 8.7$ and $6.9 \pm 11.6 \mu \mathrm{m} / \mathrm{h}$ for insulin sampled on day 1 from RIN-m microspheres and media from empty microspheres, respectively. The rate of scratch closure for monolayer scratches stimulated with insulin from day 1 monolayer RIN-m cells was $22.9 \pm 8.4 \mu \mathrm{m} / \mathrm{h}$, which was less than the closure observed in the microencapsulated group, but not significantly so. No significant difference in rate of scratch closures was observed for keratinocyte monolayers treated with insulin-conditioned media sampled from RIN-m microspheres on days 1,7 , or 21 .

Similar results were observed for keratinocyte scratches treated with insulin-conditioned media from AtT-20ins microspheres. A significantly greater rate of scratch closure was observed in scratches stimulated with insulin released from day 1 AtT-20ins microspheres $(19.8 \pm 11.7 \mu \mathrm{m} / \mathrm{h})$ compared with scratches treated with insulin released from AtT-20ins monolayer cells $(18.6 \pm 9.5 \mu \mathrm{m} / \mathrm{h})$ or negative control empty microspheres $(6.9 \pm 11.6 \mu \mathrm{m} / \mathrm{h})$ (Fig. 5B). Insulin-conditioned media sampled on day 7 from AtT20ins microspheres also showed a significant rate of scratch closure $(19.2 \pm 11.1 \mu \mathrm{m} / \mathrm{h})$ compared with control empty microspheres $(6.9 \pm 11.6 \mu \mathrm{m} / \mathrm{h})$. The rate of closure in scratches treated with insulin sampled on day 21 from AtT20ins microspheres was not significantly different from the rate of closure in scratch wounds treated with media from empty microspheres.

Empty microspheres served as insulin-free negative controls and failed to demonstrate any stimulation of cell migration across the scratches.

\section{In vivo assessment of wound closure in diabetic mice}

Gross examination showed an initial increase in wound area due to skin elasticity of the obese diabetic mice. Animals treated with RIN-m microspheres showed statistically significant acceleration in wound closure by POD $7(5.07 \% \pm$ $19.5 \%$ ) compared with AtT-20ins and control groups (Fig. 7B). By POD 21 wound closures for RIN-m, AtT-20ins, and control groups were $84.3 \% \pm 13.62 \%, 57.4 \% \pm 36.2 \%$, and

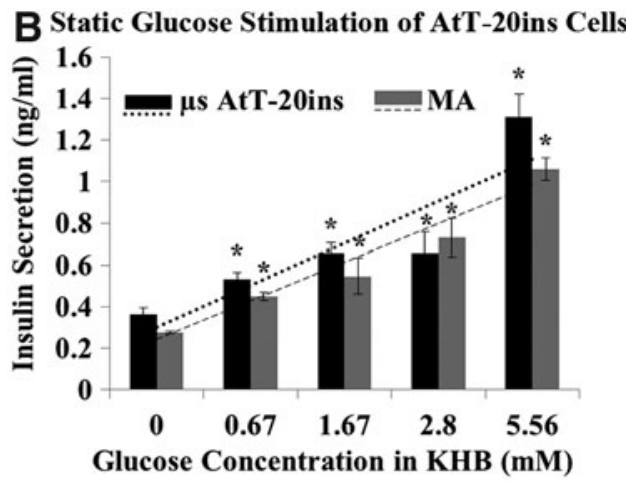

FIG. 3. Static glucose stimulation of (A) RIN-m and (B) AtT-20ins cells. Trend lines show that glucose secretion from AtT-20ins cells is increasing with increasing glucose. Trend lines fit to RIN-m cells are relatively flat, indicating no response to glucose stimulation. Asterisks show statistically significant differences $(p<0.05)$ in insulin secretion between incremental glucose concentrations versus control $(0 \mathrm{mM})$. Error bars show standard error of mean. MA, monolayer AtT20ins cells; MR, monolayer RIN-m cells. 

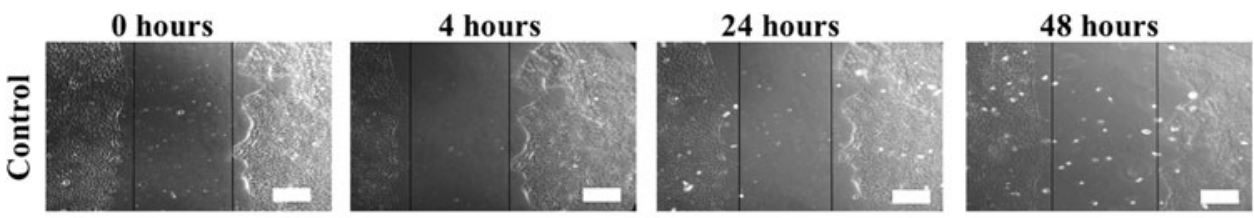

FIG. 4. Representative bright-field images of scratches in monolayer keratinocytes at $0,4,24$ and $48 \mathrm{~h}$ following stimulation by media from empty microspheres (control) and insulincontaining conditioned media from MR, MA, $\mu$ s RIN-m cells on day 1 ( $\mu \mathrm{s}-\mathrm{R} 1)$, and $\mu \mathrm{s}$ AtT-20ins cells on day 1 ( $\mu$ s-A1). Black lines depict scratch margins. Scale bars $=100 \mu \mathrm{m}$.
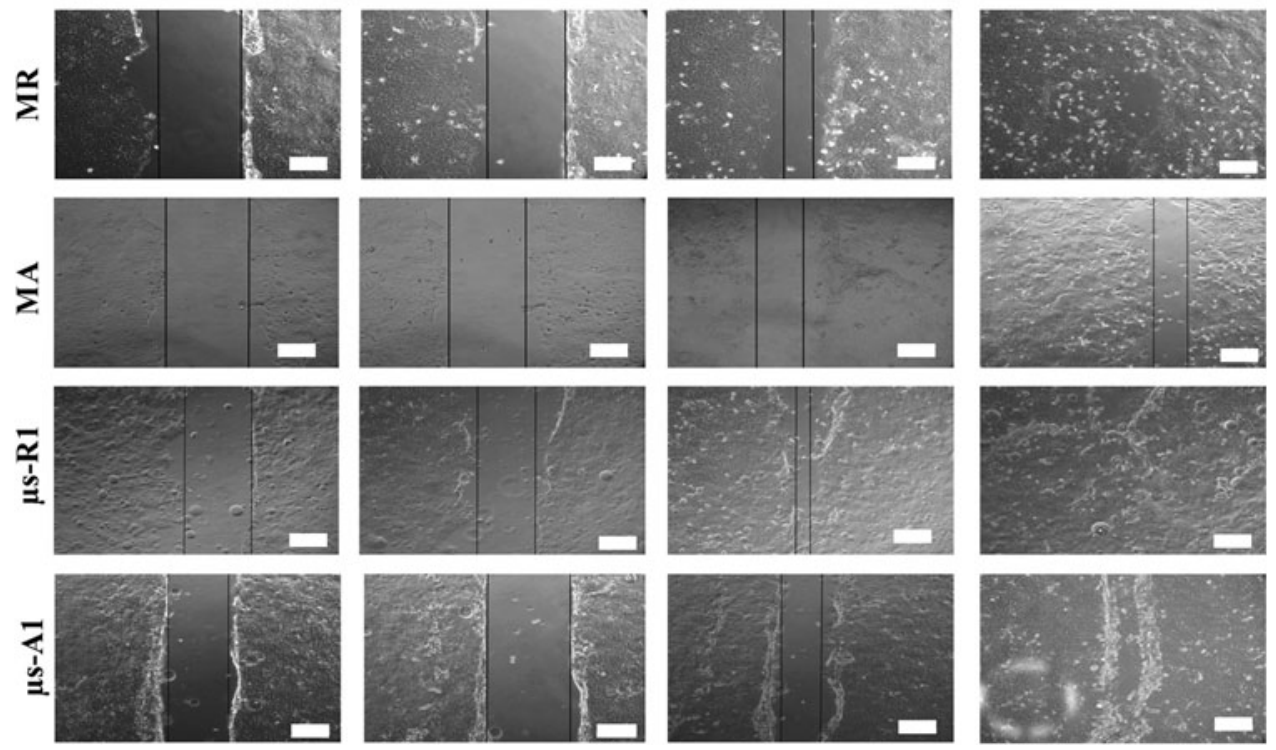

$72.98 \% \pm 7.01 \%$, respectively. Complete wound closure was achieved by POD 28 in all animals $(n=3)$ treated with RIN-m microspheres, while wound closures were $89.3 \% \pm 15.33 \%$ and $94.39 \% \pm 2.06 \%$ in AtT-20ins-treated animals $(n=3)$ and negative control animals $(n=3)$, respectively. Large standard deviations in wound closures were observed in AtT-20instreated animals. In this group, complete wound closure was achieved in two animals by POD 35, while in the third animal, wound closure was $82 \%$.

\section{Histological analysis}

After sacrifice on POD 35, skin tissue was excised around the edges of the wounded area for histological analysis. Tissue sections were stained with $\mathrm{H} \& \mathrm{E}$ for morphological analysis and PASR stain for collagen fiber density (Fig. 8). Microencapsulated insulin-secreting cells accelerated wound closure and $\mathrm{H} \& \mathrm{E}$ sections showed that the epidermis was three to five cells thick in both treatment groups, while it was only one to two cells thick in the empty microsphere control group. Quantification of $\mathrm{H} \& \mathrm{E}$ sections revealed that the epidermis was significantly thicker in animals treated with RIN-m microspheres $(42.7 \pm 10.37 \mu \mathrm{m})$ and AtT-20ins microspheres $(44.15 \pm 10.26 \mu \mathrm{m})$ compared with the negative control animals $(29.98 \pm 7.96 \mu \mathrm{m})$ (Fig. 8G). No statistically significant difference was observed in dermal thickness between the treatment and control groups (Fig. 8H); however, when the density of collagen fibers was analyzed in the PASR-stained sections, collagen fiber density (percent area) was significantly higher in RIN-m $(83.74 \% \pm 2.7 \%)$ and AtT-
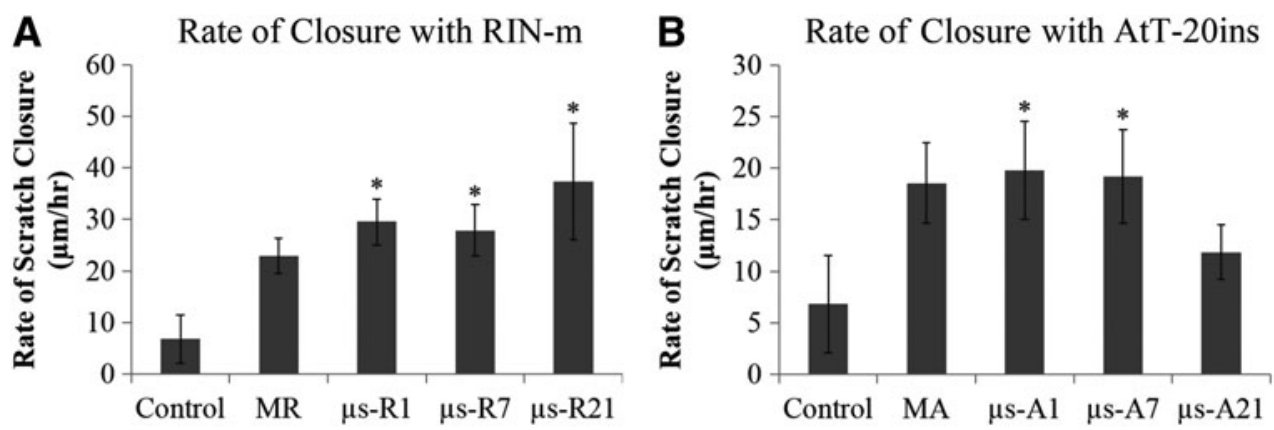

FIG. 5. Quantification of keratinocyte scratch assays of cell migration and insulin bioactivity. (A) Rate of scratch closure following stimulation by media from empty microspheres (control) and insulin-containing conditioned media sampled from MR and $\mu$ s RIN-m cells on days 1, 7, and 21 ( $\mu \mathrm{s}-\mathrm{R} 1, \mu \mathrm{s}-\mathrm{R} 7$, and $\mu \mathrm{s}-\mathrm{R} 21$, respectively). (B) Rate of scratch closure following stimulation by media from empty microspheres (control) and insulin-containing conditioned media sampled from MA and $\mu$ s AtT-20ins cells on days 1, 7, and 21 ( $\mu \mathrm{s}-\mathrm{A} 1, \mu \mathrm{s}-\mathrm{A} 7$, and $\mu \mathrm{s}-\mathrm{A} 21)$. Both cell types accelerated scratch closure, although conditioned media from RIN-m cells demonstrated a more profound effect on scratch closure than conditioned media from AtT-20ins. Asterisks indicate statistically significant differences $(p<0.05)$ between the indicated condition(s) and control. Error bars show standard error of mean. 

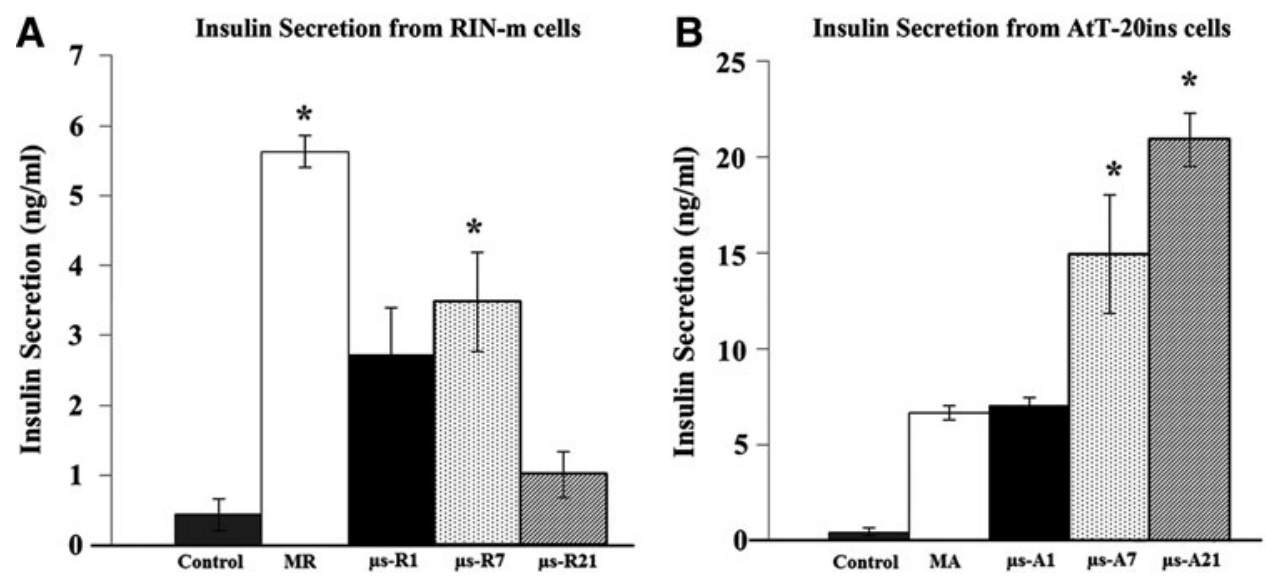

FIG. 6. Concentration of insulin in insulin-conditioned media sampled from (A) MR and $\mu$ s RIN-m cells on days 1 , 7, and 21 ( $\mu \mathrm{s}-\mathrm{R} 1, \mu \mathrm{s}-\mathrm{R} 7$, and $\mu \mathrm{s}-\mathrm{R} 21$, respectively) and (B) MA and $\mu$ AtT-20ins cells on days 1,7 , and 21 ( $\mu$ s-A1, $\mu \mathrm{s}-\mathrm{A} 7$, and $\mu \mathrm{s}-\mathrm{A} 21)$. Empty microspheres (control) served as insulin-free negative controls. Asterisks indicate statistically significant differences $(p<0.05)$ between the indicated condition(s) and control. Error bars show standard error of mean.

20ins $(79.95 \% \pm 3.7 \%)$ treatment groups compared with the control group $(67.35 \% \pm 2.74 \%)$ (Fig. 8I).

\section{Discussion}

Wound healing is a dynamic process that occurs in a wellorchestrated synchrony of events that overlap and are interdependent. Any biological or temporal defect may affect

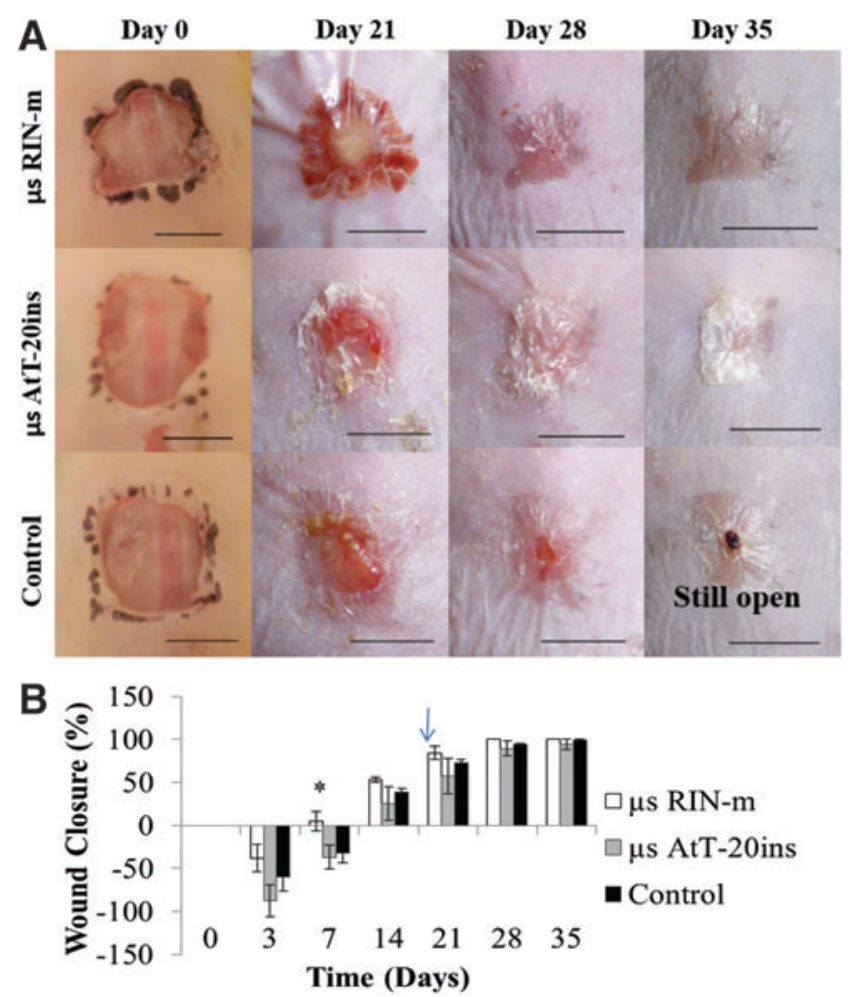

FIG. 7. Representative images and quantification of wound closure over time. (A) Gross appearance and (B) percent wound closure. Images show wounds before Tegaderm ${ }^{\mathrm{TM}}$ application and after its removal. The dark stain around the wound on day 0 is from a skin marker to define the wound area. Arrow shows microsphere removal on postoperative day 16. Asterisks indicate statistically significant differences $(p<0.05)$ between microencapsulated cells versus control. Error bars show standard error of mean. Scale bars $=1 \mathrm{~cm}$. Color images available online at www.liebertpub.com/tea wound healing. Tight regulation and resolution of the inflammatory response, as well as initiation of reepithelialization, are critical to effective wound healing. Previous studies have reported that topical application of insulin accelerates wound healing by regulating the hyperglycemic wound environment and by promoting growth and proliferation of keratinocytes, fibroblasts, and endothelial cells in both diabetic and nondiabetic patients. However, current approaches require repeated applications that increase the chances of infecting the wound with each opening of the wound dressing for every application. Cells that secret insulin into the wound area provide a solution to this problem. In this study, we presented a novel system that encapsulates constant or glucose-dependent insulin-secreting cells within synthetic hydrogels formed from PEGDA. This approach maintains cell viability and insulin secretory characteristics of the cells while at the same providing a bioinert nonimmunogenic barrier. Moreover, insulin secretion is modulated in a sustained manner, eliminating the need for multiple applications as required in topical insulin ointments.

Cell viability and cytotoxicity assays showed that the majority of cells survived the microencapsulation process. Data showed a gradual decline in viability over 21 days, which is expected since cells do not proliferate in these hydrogels. The total number of insulin-releasing cells is more significant than the percentage of live cells, as demonstrated by the bioactivity and wound healing studies. Glucose stimulation studies demonstrated that the encapsulated cells maintained their insulin secretory characteristics and the microspheres' hydrogel mesh permitted free diffusion of insulin through the microspheres. The insulin molecule has a molecular weight of $5808 \mathrm{Da}$ and a molecular radius of $1.34 \mathrm{~nm}^{28}$ Free diffusion of insulin from microspheres as confirmed by our data was as expected since the mesh size of the $10 \% 10 \mathrm{kDa}$ PEGDA that we used has a mesh size of $28 \mathrm{~nm}^{29}$ Thus, no statistically significant difference in insulin secretion was observed between monolayer insulin-secreting cells and microencapsulated insulin-secreting cells.

Once the release of insulin from the microspheres was confirmed, it was also important to determine whether the released insulin remained bioactive, which was accomplished by demonstrating that the released insulin was capable of stimulating a wound healing response. The keratinocyte scratch assay is an in vitro wound healing model and stimulation of HaCaT cell migration by insulin is an accepted 

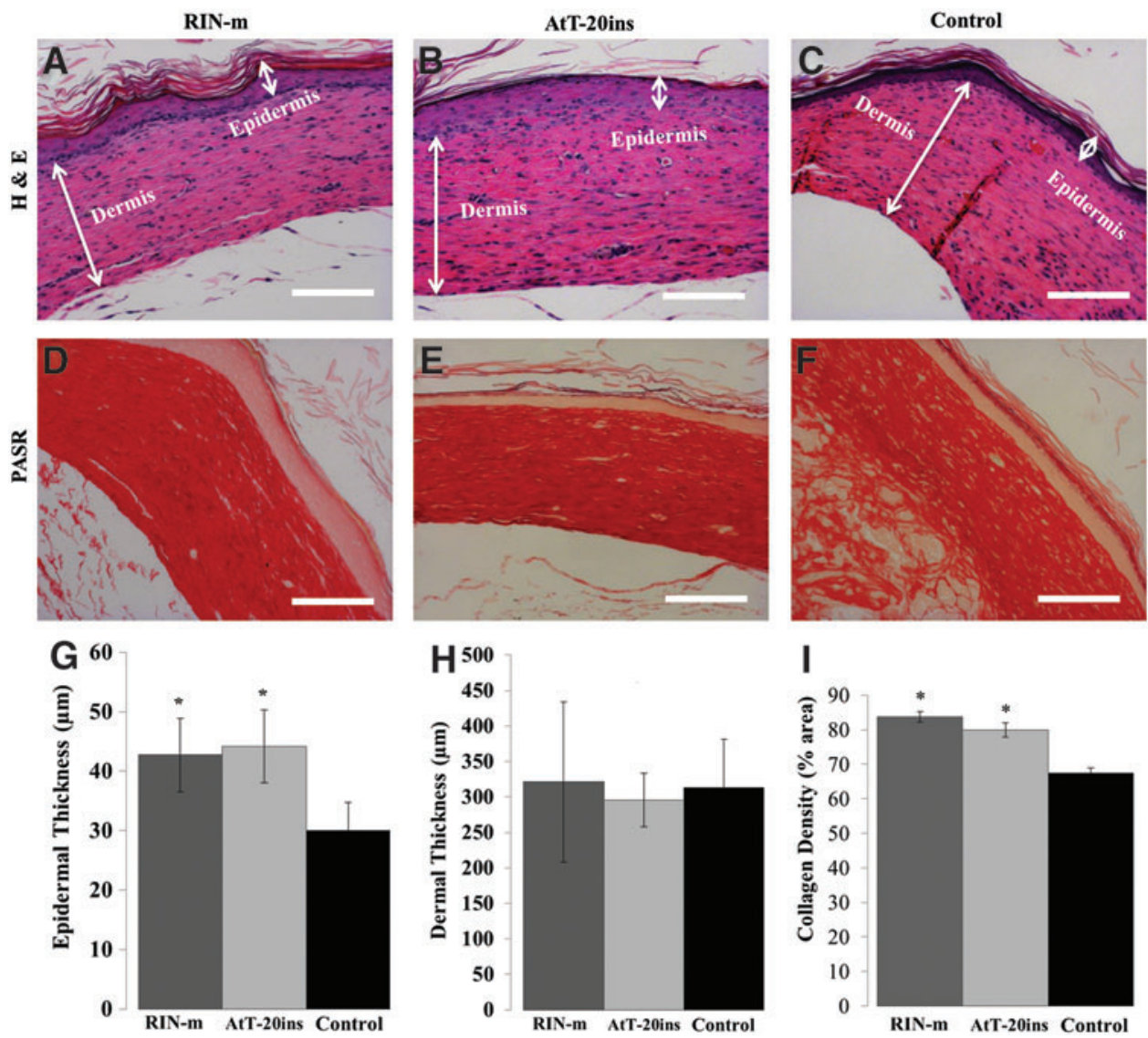

FIG. 8. Histological analysis of harvested wounds. Hematoxylin and eosin (H \& E)-stained wound tissue sections of animals treated with (A) RIN-m microspheres, (B) AtT-20ins microspheres, and (C) empty microspheres (control). Picric Acid Sirius Red (PASR)-stained wound tissue sections of animals treated with (D) RIN-m microspheres, (E) AtT-20ins microspheres, and (F) empty microspheres (control). Quantification of (G) epidermal thickness, (H) dermal thickness, and (I) collagen fiber density. Although there is no statistical difference in dermal thickness between groups, epidermal thickness in treated wounds is statistically greater than control. Collagen fiber densities in treated groups are also statistically greater than control. Asterisks indicate statistically significant differences $(p<0.05)$ between treated and control wounds. Error bars show standard error of mean. Scale bars $=50 \mu \mathrm{m}$. Color images available online at www.liebertpub.com/tea

indicator of insulin bioactivity over time and its ability to promote wound healing. Our microencapsulated RIN-m and AtT-20ins cells on average secrete $2.4 \pm 0.2 \mathrm{ng} / \mathrm{mL}(0.4 \mathrm{nM})$ insulin and $14.3 \pm 1.36 \mathrm{ng} / \mathrm{mL}(2.4 \mathrm{nM})$ insulin, respectively (Fig. 6), which is comparable with the typical $10^{-7} \mathrm{M}$ concentration of insulin used to stimulate keratinocyte migration. $^{30,31}$ The bioactivity of insulin released from microspheres was maintained over time as indicated by its continued ability to accelerate scratch closure.

Specifically, cell migration studies demonstrated that the insulin released from microencapsulated RIN-m cells remained bioactive for at least 21 days, which is sufficient time for a wound to completely heal. The rate of closure observed in scratches treated with insulin released from days 1, 7, and 21 RIN-m microspheres was not significantly different between groups, but each group was significantly greater than the (control) empty microsphere group $(p<0.05)$. Decreases in the rate of scratch closure were observed in scratches treated with insulin collected on day 21 from microencapsulated AtT-20ins cells compared with scratches treated with insulin collected on day 1 . This reduction in the rate of scratch closure could be due to loss of microspheres during media collection or loss of cell viability over time and therefore reduced concentration of insulin in the sample used to stimulate HaCaT cell migration. Further experiments will be conducted to elucidate these results.

In nondiabetic mice, the relatively large $1 \mathrm{~cm}^{2}$ fullthickness excisional wound has been shown to take 25 days to heal. ${ }^{32}$ In the diabetic mice in this study, the untreated wound takes over 35 days to heal, $40 \%$ longer. Thus, although the wounds show $94 \%$ closure, this closure is well past the normal time it should have taken. The percentage wound closure calculated for each group demonstrated a trend of accelerated closure in insulin-treated animals before removal of microspheres on POD 16, after which negative control (empty microspheres) animals showed similar wound closure dynamics. Insulin is typically applied at $0.03 \mathrm{U}$ in $20 \mu \mathrm{L}$ saline to treat excisional wounds in mice, which is equivalent to $52.05 \mathrm{ng} / \mathrm{mL}$, while our study reports accelerated wound healing at much lower concentration. 9,30

Histology showed no evidence of immune reaction to empty PEGDA hydrogel microspheres or those containing insulin-secreting cells. The large standard deviation in percentage wound closure for microencapsulated AtT-20ins cells might be attributed to the fact that these cells grow in clusters, which may result in varying cell densities within 
microspheres between animals. This is due to the fact that our microencapsulation method is not $100 \%$ efficient and more reproducibly encapsulates individual cells than clusters. In future, this could be rectified by encapsulating cells in thin sheets using molds and a method that does have $100 \%$ encapsulation efficiency; however, based on our results, we will proceed with RIN-m cells, which demonstrated superior wound healing and do not grow in clusters. The healing attained with RIN-m cells suggests that the presence of insulin is sufficient for wound healing and does not need to be tailored to the glucose environment of the wound bed.

\section{Conclusions}

In this study, a system for accelerated wound healing, in which insulin-secreting cells encapsulated into PEGDA hydrogel microspheres, was evaluated. This permitted prolonged insulin release within the target site. Microsphere encapsulation prevented immune clearance and migration, keeping the microencapsulated cells in the desired location. Thus, the combination of insulin-releasing cells and PEGDA hydrogel microencapsulation provides a novel method for delivering a steady constant dose of insulin to a wound. Future studies will explore dose responses, various hydrogel geometries, and insulin-mediated induction of downstream signaling molecules. Our system is the first cell-based insulin treatment of its kind to speed wound closure, demonstrating that this system is a feasible method to accelerate wound healing and it may impact insulin-driven wound healing approaches to come.

\section{Acknowledgment}

Ayesha Aijaz was supported by a Fulbright Fellowship.

\section{Disclosure Statement}

No competing financial interests exist.

\section{References}

1. Church, D., Elsayed, S., Reid, O., Winston, B., and Lindsay, R. Burn wound infections. Clin Microbiol Rev 19, 403, 2006.

2. Li, J., Chen, J., and Kirsner, R. Pathophysiology of acute wound healing. Clin Dermatol 25, 9, 2007.

3. McCarty, S.M., Cochrane, C.A., Clegg, P.D., and Percival, S.L. The role of endogenous and exogenous enzymes in chronic wounds: a focus on the implications of aberrant levels of both host and bacterial proteases in wound healing. Wound Repair Regen 20, 125, 2012.

4. Apikoglu-Rabus, S., Izzettin, F.V., Turan, P., and Ercan, F. Effect of topical insulin on cutaneous wound healing in rats with or without acute diabetes. Clin Exp Dermatol 35, 180, 2010.

5. Rosenthal, S.P. Acceleration of primary wound healing by insulin. Arch Surg 96, 53, 1968.

6. Shanley, L.J., McCaig, C.D., Forrester, J.V., and Zhao, M. Insulin, not leptin, promotes in vitro cell migration to heal monolayer wounds in human corneal epithelium. Invest Ophthalmol Vis Sci 45, 1088, 2004.

7. Hermann, C., Assmus, B., Urbich, C., Zeiher, A.M., and Dimmeler, S. Insulin-mediated stimulation of protein kinase Akt: a potent survival signaling cascade for endothelial cells. Arterioscler Thromb Vasc Biol 20, 402, 2000.
8. Rabinowitch, I.M. The influence of infection upon the reaction of the diabetic to insulin treatment. Can Med Assoc J 14, 481, 1924.

9. Rabinowitch, I.M. Simultaneous respiratory exchange and blood sugar time curves. Arch Surg 26, 696, 1933.

10. Chen, X., Liu, Y., and Zhang, X. Topical insulin application improves healing by regulating the wound inflammatory response. Wound Repair Regen 20, 425, 2012.

11. Brem, H. Cellular and molecular basis of wound healing in diabetes. J Clin Invest 117, 1219, 2007.

12. Liu, Y., Petreaca, M., and Martins-Green, M. Cell and molecular mechanisms of insulin-induced angiogenesis. J Cell Mol Med 13, 4492, 2009.

13. Lima, M.H.M., Caricilli, A.M., de Abreu, L.L., Araújo, E.P., Pelegrinelli, F.F., Thirone, A.C.P., Tsukumo, D.M., Pessoa, A.F.M., dos Santos, M.F., and de Moraes, M.A. Topical insulin accelerates wound healing in diabetes by enhancing the AKT and ERK pathways: a double-blind placebo-controlled clinical trial. PLoS One 7, e36974, 2012.

14. Greenway, S.E., Filler, L.E., and Greenway, F.L. Topical insulin in wound healing: a randomised, double-blind, placebo-controlled trial. J Wound Care 8, 526, 1999.

15. Madibally, S.V., Solomon, V., Mitchell, R.N., Van De Water, L., Yarmush, M.L., and Toner, M. Influence of insulin therapy on burn wound healing in rats. J Surg Res 109, 92, 2003.

16. Rezvani, O., Shabbak, E., Aslani, A., Bidar, R., Jafari, M., and Safarnezhad, S. A randomized, double-blind, placebocontrolled trial to determine the effects of topical insulin on wound healing. Ostomy Wound Manage 55, 22, 2009.

17. Sen, C.K., Gordillo, G.M., Roy, S., Kirsner, R., Lambert, L., Hunt, T.K., Gottrup, F., Gurtner, G.C., and Longaker, M.T. Human skin wounds: a major and snowballing threat to public health and the economy. Wound Repair Regen 17, 763, 2009.

18. Procházka, V., Gumulec, J., Jaluvka, F., Salounová, D., Jonszta, T., Czerny, D., Krajca, J., Urbanec, R., Klement, P., and Martinek, J. Cell therapy, a new standard in management of chronic critical limb ischemia and foot ulcer. Cell Transplant 19, 1413, 2010.

19. Singh, N., Armstrong, D.G., and Lipsky, B.A. Preventing foot ulcers in patients with diabetes. JAMA 293, 217, 2005.

20. Amputee Coalition of America. National limb loss information fact sheet; diabetes and lower extremity amputations. 2008. Available at www.amputee-coalition.org/fact_sheets/ diabetes_leamp.html. Accessed June 18, 2015.

21. Olekson, M.A. Strategies for improving growth factor function in diabetic wounds. 2014. Available at https://rucore .libraries.rutgers.edu/rutgers-lib/45385/. Accessed June 16, 2015.

22. Kepsutlu, B., Nazli, C., Bal, T., and Kizilel, S. Design of bioartificial pancreas with functional micro/nano-based encapsulation of islets. Curr Pharm Biotechnol 15, 590, 2014.

23. Schwartz, S., and Mulgrew, P. A single-center phase I/II study of PEG-encapsulated islet allografts implanted in patients with type I diabetes (study NCT00260234). November 2005. Available at www.clinicaltrials.gov. Accessed February 1, 2015.

24. Cruise, G.M., Hegre, O.D., Lamberti, F.V., Hager, S.R., Hill, R., Scharp, D.S., and Hubbell, J.A. In vitro and in vivo performance of porcine islets encapsulated in interfacially photopolymerized poly(ethylene glycol) diacrylate membranes. Cell Transplant 8, 293, 1999. 
25. Olabisi, R.M., Lazard, Z.W., Franco, C.L., Hall, M.A., Kwon, S.K., Sevick-Muraca, E.M., Hipp, J.A., Davis, A.R., Olmsted-Davis, E.A., and West, J.L. Hydrogel microsphere encapsulation of a cell-based gene therapy system increases cell survival of injected cells, transgene expression, and bone volume in a model of heterotopic ossification. Tissue Eng Part A 16, 3727, 2010.

26. Franco, C.L., Prince, J., and West, J.L. Development and optimization of a dual-photoinitiator, emulsion-based technique for rapid generation of cell-laden hydrogel microspheres. Acta Biomater 7, 3267, 2011.

27. Hunter, J.M., Kwan, J., Malek-Ahmadi, M., Maarouf, C.L., Kokjohn, T.A., Belden, C., Sabbagh, M.N., Beach, T.G., and Roher, A.E. Morphological and pathological evolution of the brain microcirculation in aging and Alzheimer's disease. PLoS One 7, e36893, 2012.

28. Bromberg, L., Rashba-Step, J., and Scott, T. Insulin particle formation in supersaturated aqueous solutions of poly(ethylene glycol). Biophys J 89, 3424, 2005.

29. Liao, H., Munoz-Pinto, D., Qu, X., Hou, Y., Grunlan, M.A., and Hahn, M.S. Influence of hydrogel mechanical properties and mesh size on vocal fold fibroblast extracellular matrix production and phenotype. Acta Biomater 4, 1161, 2008.

30. Liu, Y., Petreaca, M., Yao, M., and Martins-Green, M. Cell and molecular mechanisms of keratinocyte function stimulated by insulin during wound healing. BMC Cell Biol 10, 1, 2009.

31. Benoliel, A.M., Kahn-Perles, B., Imbert, J., and Verrando, $P$. Insulin stimulates haptotactic migration of human epidermal keratinocytes through activation of NF-kappa B transcription factor. J Cell Sci 110, 2089, 1997.

32. Sarkar, A., Tatlidede, S., Scherer, S.S., Orgill, D.P., and Berthiaume, F. Combination of stromal cell-derived factor-1 and collagen-glycosaminoglycan scaffold delays contraction and accelerates reepithelialization of dermal wounds in wild-type mice. Wound Repair Regen 19, 71, 2011.

Address correspondence to: Ayesha Aijaz, BS Department of Biomedical Engineering Rutgers University 599 Taylor Road Piscataway, NJ 08854

E-mail: ronke.olabisi@rutgers.edu

Received: February 11, 2015 Accepted: July 31, 2015

Online Publication Date: September 4, 2015 